\title{
Expanding socio-cultural identity research in sport psychology: The potential of athlete autobiographies
} Ampliando la investigación sobre identidad sociocultural en la psicología del deporte: El potencial de las autobiografías de los atletas

\author{
Kerry R. McGannon \\ Laurentian University \\ Brett Smith \\ Durham University
}

\begin{abstract}
Within the cultural sport psychology (CSP) genre, researchers have considered multiple and intersecting athlete identity expression to enhance sport participation, inclusion and performance. The aim with the present paper was to build upon, and expand a CSP research agenda that focuses on socially constructed identities, through exploring narrative inquiry in conjunction with athlete autobiographies as data (re)sources. To accomplish this aim, we outline the central tenets of narrative inquiry and convergences with CSP, followed by an overview of autobiography. We then draw on autobiography research from cultural studies and sport psychology in relation to two central areas of concern in CSP: gender issues with a focus on women and health and well-being issues in sport. We conclude with some aspirations for future research on autobiographies grounded in narrative inquiry, to expand a CSP research agenda.
\end{abstract}

Keywords: Narrative inquiry; Cultural sport psychology; Qualitative research; Athletics

\section{Resumen}

En la psicología cultural del deporte (PCD), los investigadores han considerado la expresión múltiple e intersectorial de la identidad del atleta para mejorar la participación, la inclusión y el rendimiento deportivo. El objetivo del presente documento era aprovechar y ampliar un programa de investigación de la PCD centrado en las identidades construidas socialmente, mediante la exploración de la indagación narrativa junto con las autobiografías de los atletas como fuentes de datos. Para ello, esbozamos los principios centrales de la indagación narrativa y las convergencias con la PCD, seguido de una visión general de la autobiografía. A continuación, nos basamos en la investigación autobiográfica de los estudios culturales y la psicología del deporte en relación con dos esferas centrales de interés en la PCD: las cuestiones de género, con especial atención a las mujeres, y la salud y bienestar en el deporte. Concluimos con algunas aspiraciones para futuras investigaciones sobre autobiografías basadas en la indagación narrativa, para ampliar una agenda de investigación de CSP.

Palabras clave: Indagación narrativa; Psicología cultural del deporte; Investigación cualitativa; Atletismo 


\section{INTRODUCTION}

The study of 'self-identity' and physical activity participation has a long history in sport psychology because people have been shown to think, feel and behave in particular ways, within physical activity contexts, in light of 'who they are' (i.e., self-identity) (McGannon \& Spence, 2010; Slater et al., 2015). Researchers exploring identity within sport psychology popularized the topic in the 1990s, using quantitative methods (e.g., questionnaires) to explore 'athletic identity' as a cognitive structure and/or social role formed through interpersonal interactions (e.g., coaches, parents, teammates) (see Brewer et al., 1993). Additional work in the 1990 s explored self-identity as a 'multidimensional' social cognitive conception, formed and/or expressed within, and across, sport contexts, which remains a popular view in contemporary sport psychology identity research (see Ronkainen et al., 2015 for an overview).

In the early 2000s, cultural studies and feminist perspectives were used by sport psychology scholars to draw attention to aspects of identity privilege (e.g., White male, Eurocentric, heterosexual) (Butryn, 2002; Fisher et al., 2003) and the marginalization and/or exclusion of identities in sport (e.g., nonWhite, lesbian, female) (Gill, 2001; Krane, 2001). Contemporary critical identity work within 'cultural sport psychology' (CSP) is grounded in cultural studies and feminist scholarship. Within this work, socially constructed identities and power issues are centralized (McGannon \& Smith, 2015; Ryba et al., 2010). CSP researchers and practitioners are encouraged to account for culture (e.g., values, language use, roles, sport meanings) in the formation and expression of identity, in light of a dynamic sport landscape that includes athletes from multiple cultural backgrounds (Blodgett et al., 2015; McGannon et al., 2014; Ryba et al., 2013).

Despite CSP's emphasis on fluid socio-cultural identity expression and inclusion, sport remains an unequal playing field where some identities are privileged (e.g., White, male, heterosexual, certain masculinities) over others (e.g., nonWhite, female, non-heterosexual, certain femininities) (Blodgett et al., 2017; McGannon, Tatarnic et al., 2019; Schinke et al., 2016). Such privileging results in silencing and/or marginalizing identities that do not conform to notions of what it means to be an 'athlete' and/or sport participant, compromising athletic potential, participation and well-being (Blodgett et al., 2017; McGannon, Schinke, et al., 2019; Ryba et al., 2013). In light of its focus on cultural identities, power issues and culturally sensitive practice, CSP is useful to facilitate dialogues among physical activity participants and social scientists. These dialogues can open up additional understanding of, and solutions to, identity expression and inclusion in sport contexts (Schinke et al., 2016). In order to ex- 
pand understanding of cultural identities and inclusion practices, an openness to methodological variation grounded in various epistemologies (e.g., social constructionism, post-positivism) has been advocated within CSP research (Blodgett et al., 2015; McGannon \& Smith, 2015; Ryba et al., 2010; Schinke et al., 2016).

One way to expand cultural identity work within CSP is to use "critical qualitative research methodologies' which focus on a nuanced analysis of identity, experience and culture (McGannon \& Smith, 2015; Ronkainen et al., 2016). The use of critical qualitative methodologies aligns with the goals of CSP to blend theory, experience and culture to accommodate the study of identities as socially constructed (Blodgett et al., 2015; Ryba et al., 2010). The aim with the present paper is to build upon one theoretical perspective making in-roads in sport psychology to study cultural identities - narrative inquiry (Carless \& Douglas, 2013; Smith \& Sparkes, 2009) - in conjunction with one storied form of data that infuses personal and sociocultural realms: athlete autobiographies (Sparkes \& Stewart, 2016). While the use of narrative inquiry in conjunction with autobiography is growing within sport psychology (see McGannon \& McMahon, 2019), no published work has yet put them explicitly into dialogue to explore what they afford sport psychology and CSP research. The intent with the present paper is to explore these possibilities and prompt additional empirical investigations working at the intersection of narrative inquiry and autobiographic studies to explore identity and/or cultural issues in sport psychology. Because narrative inquiry is a methodology that takes a novel creative approach to conceptualizing and studying identities and lives within stories, exploring autobiographies as data (re)sources may open up new research questions within sport psychology.

To accomplish the above aims, an overview of narrative inquiry is provided and some key convergences with CSP. To further show the potential of narrative inquiry for centralizing the study of socially constructed identities and sport participation, we outline autobiography in relation to narrative inquiry. We then discuss empirical research from cultural studies and sport psychology in relation to two central areas of concern in CSP research: gender issues and women's sport and athlete health and well-being. We chose to centralize women within the sport and gender nexus because women athlete's stories need to come to the fore in light of the tendency to centralize men's sporting stories (McGannon, Schinke et al., 2019; Stewart, 2017). We also centralized athlete health and well-being in light of recent calls to explore these issues more deeply with a cultural lens (McGannon \& McMahon, 2019; Schinke et al., 2018). We conclude with some aspirations for forms of CSP research working at the inter- 
section of narrative inquiry and autobiography. These ideas are offered not as 'definitive ways' to conduct CSP research, but as considerations amongst a range of epistemological and methodological possibilities as well as data forms in sport psychology research, that may be used to centralize identity work and culture in sport psychology and CSP.

\section{NARRATIVE INQUIRY: CENTRAL TENetS AND LINKS WITH CSP}

Narrative inquiry is a psychosocial approach within the social sciences, focusing on the study of stories (Smith, 2016; Smith \& Sparkes, 2009). Within narrative inquiry, stories are viewed as cultural sites of analysis because people use them to make sense of their self-identities (Frank, 2013; Smith \& Sparkes, 2009). As the terms are used here, a story is delineated as a tale people tell about themselves or others and a narrative is a culturally available resource; "people tell stories, not narratives" (Smith \& Sparkes, 2009, p. 2). A central tenet of narrative inquiry is that people use stories to make sense of who they are (i.e., selfidentities), and how they might behave, by drawing on social and cultural narratives (Smith, 2010; Smith \& Sparkes, 2009). Narratives are thus resources that provide people with a template from which to build and structure meaning, experience, and identity-related stories, as well as understand the stories they hear about others (Frank, 2013; Smith, 2016).

Within narrative inquiry, self-identity conceptualization is dependent on the ontology (i.e., view of reality) and epistemology (i.e., way of knowing about reality) (Smith \& Sparkes, 2008, 2009). A psychosocial approach to narrative conceptualizes self-identity stories as originating from within the person's psyche/mind due to adhering to a realist ontology and constructivist epistemology (Smith \& Sparkes, 2008). Narrative researchers using a psychosocial approach view self-stories as windows into worlds of storytellers, and thus study stories and narratives, as revealing aspects of identity (Smith, 2010; Smith \& Sparkes, 2008). Within a social relational approach, self-identity within narrative inquiry are conceptualized within a relativist ontology and social constructionist epistemology, which prioritizes narrative resources as constructing self-identity and experiences (McGannon \& Smith, 2015; Smith \& Sparkes, 2008). Within a social relational view, the focus "shifts from selves and identities as individualistic, real, and interior-based, to them being constructions derived from narratives and performed in relationships" (Smith \& Sparkes 2009, p. 5).

Although our own work favours a relativist approach to narrative inquiry when exploring self-identity in physical activity contexts, a realist psychosocial approach to narrative inquiry in sport psychology is equally useful to explore identity topics in CSP. We will expand upon these subtle differences in narra- 
tive approach when outlining autobiographical examples in sport research. Regardless of whether one subscribes to a psychosocial or social relational approach in CSP research, a key convergence of CSP with narrative inquiry is that studying stories affords the opportunity to explore the nuanced ways in which people use stories to create and express identities and sporting lives. When people in sport contexts tell, or witness, identity transformative stories within particular narrative resources, for example, emancipation and change is possible (Smith et al., 2016), because stories have associated action, and reactions, depending on the narrative resources that frame them (Frank, 2013). Conversely, telling and/or listening to stories that are oppressive or health compromising within sport, can solidify truths, but also expose problematic and discriminatory practices that negatively impact well-being and performance (Carless \& Douglas, 2013; McGannon \& McMahon, 2019). Studying stories with a narrative sensibility within CSP opens up possibility for marginalized identities to come to the fore, making social inclusion and change a possibility (Blodgett et al., 2017; McGannon \& Smith, 2015).

Relativist narrative inquiry also allows researchers to challenge the reliance on a cognitive conception of self-identity within sport psychology (McGannon \& Smith, 2015; Smith, 2010). The destabilizing of a cognitive conception of selfidentity is an additional convergence with proponents of CSP grounding their work in feminist and cultural studies. Such work challenges the status quo in terms of what counts as a research focus in sport psychology and how that focus is explored, questioning a post-positivist approach in research as the 'best' or more valid approach (McGannon \& Smith, 2015; Smith, 2016).

Narrative researchers may adopt a story analyst or storyteller approach to narrative inquiry (Smith, 2016; Smith \& Sparkes, 2009). When operating as a story analyst, the story and the narratives that frame it are treated as the objects of study. Story analysts place narratives under analysis and communicate results in the form of a realist tale to produce an analytical account of narratives (e.g., quotes from stories/narrative accounts, interpreted with researcher commentary and theory) (Smith \& Sparkes, 2009). Storytellers communicate the analysis of a story in the form of a creative analytical practice (CAP). CAP is an umbrella term for research practices that embrace creative forms of representation and writing to show layers of lived experience, emotion and theory in research findings (McMahon, 2016). Researchers using CAP from a storyteller approach produce a tale as a story in evocative, entertaining and accessible forms, such as autoethnography (i.e., personal self-story) and creative nonfiction (i.e., story created from data and themes) (Smith, 2016). From a storyteller approach, the story is analytical and theoretical in its own right; analysis 
happens within a story intentionally communicated in a way that reconfigures 'writing up results' as a medium of creative and artistic expression (McMahon, 2016; Smith, 2016). The distinction between a story analyst and a storyteller is an important one, given that both approaches are useful to learn more about, and explore representations of, identities through narrative inquiry in sport. Having said this, the approach to autobiography outlined next, and the research examples that follow, draw on a story analyst approach. We return to a storyteller approach and its potential, when outlining future possibilities for CSP research using autobiography.

\section{AUTOBIOGRAPHY}

One form of culturally rich self-story constructed within narrative resources worthy of study are athlete autobiographies (Pipkin, 2008). An 'autobiography' is a first person story told by a single narrator, which contrasts with biographies written by a third person about someone (Smith \& Watson, 2010; Sparkes \& Stewart, 2016). The study of autobiography as a cultural site links to work in literary theory, history and anthropology (Eakin, 2008; Smith \& Watson, 2010). Relevant to conceptualizing athletic identities, is that the body has been recognized as a crucial site of autobiographical knowledge and expression, as well as a textual surface on which a person's life and material experiences is inscribed (Eakin, 2008; Sparkes, 2004). Aligning with tenets of narrative inquiry, autobiographies infuse personal, social and cultural realms, because their content and ways of storytelling draw on cultural narratives for understanding and shared meaning (Eakin, 2008; Smith \& Watson, 2010).

Sporting autobiographies are commercially produced forms of celebrity autobiographies, focusing on high profile athlete's lives, providing public access to sport culture (Sparkes, 2004; Sparkes \& Stewart, 2016). Autobiographies differ from stories gathered through researcher-led interviews subsequently analysed and published with participant(s) identities concealed (McGannon \& McMahon, 2019; Sparkes \& Stewart, 2016). Sport autobiographies are in abundance, as more athletes and sports workers write about, and confess, their lives in publicly available formats (e.g. book, digital, social media, documentary film). Despite their ubiquity and cultural presence, Andrew Sparkes and Carly Stewart (2016) noted that trustworthiness of autobiographies as data (re)sources may be questioned by those grounding research in realist understandings of identity and seeking objectivity or accuracy, as they may be ghost written and/or produced for profit or sensationalism. Underscoring a lack of trust in autobiographies as data sources is the privileging of interviews as the gold standard in qualitative research (McGannon, Smith et al., 2019; Sparkes \& Stewart, 2016). 
Despite potential issues or pitfalls of autobiographies as data resources, the theoretical and methodological advantages to exploring athlete autobiographies from a story analyst approach in narrative inquiry transcend the aforementioned concerns. This is particularly the case when one considers that the public readily consumes these rich and evocative stories, which constitutes a cultural phenomenon worthy of study (Pipkin, 2008; Sparkes \& Stewart, 2016; Stewart, 2011). Moreover, when grounded in narrative inquiry, autobiographies can be studied as novel data sources and ways to explore and theorize sociocultural identities, rather than providing windows into 'true' identities, psyches and lives (Eakin, 2008; Smith \& Watson, 2010). When conceived of in this manner, autobiographies afford CSP researchers the opportunity to witness and explore cultural identities constructed within socio-cultural narrative resources.

Of additional interest to sport psychology, is that autobiographies are pedagogical resources that can be used to teach and/or show understanding through providing access to emotional life worlds of athletes (Pipkin, 2008; Sparkes, 2004). Aligning with the tenet of narrative inquiry that views stories and narratives as 'actors', autobiographies 'do things' on, and for, people (Eakin, 2008; Frank, 2013). Through public disclosure of one's story, autobiographies can facilitate critical reflections in tellers and listeners through forms of confession and exposure of silenced, stigmatized or difficult to access topics, particularly in elite sport culture (McGannon \& McMahon, 2019; Newman et al., 2016). In light of the theoretical, analytical and pedagogical potential of autobiographies, CSP researchers interested in identity and social change through providing space for people to tell and witness stories, have much to gain by studying athlete autobiographies grounded in narrative inquiry.

\section{ResearCh ON ATHLete Autobiographies}

Since Sparkes and Stewart (2016) outlined the analytical, theoretical and pedagogical potential of autobiographies in the sport and exercise sciences, published autobiographic studies have gained traction in sport psychology. In what follows, we draw on examples of autobiography studies to show the potential of autobiography research for expanding identity work and CSP goals. We present these studies under two topics in need of deeper cultural exploration in sport psychology: gender issues in women's sport and health and wellbeing issues in sport. 


\section{Gender Issues in Women's Sport}

As noted in our introduction, researchers in sport studies, sport psychology, and CSP, have drawn attention to inequalities in sport, particularly from a gender perspective (Blodgett et al., 2017; Fisher et al., 2003; Gill, 2001; Krane, 2001; McGannon, Schinke et al., 2019). From a relativist ontology, the notion that gender reflects particular attitudes and behaviours based on a binary of masculinity and femininity (i.e., male or female) grounded in biology (i.e., sex) is challenged (Butler, 2006). Instead, gender is performed via expected behaviours and linked to a range of sexualities, solidifying what it means to be 'feminine' and 'masculine' (Butler, 2006). These meanings further depend on the narratives drawn upon to make sense of gendered performances and sexuality (Butler, 2006; McGannon, Schinke et al., 2019). Despite the possibility for a range of gender and sexuality expressions, within women's sport, compulsory heterosexuality (i.e., people are assumed to be attracted to the opposite sex), limited forms of femininity (e.g., passive, demure, quiet), and physicality (e.g., less muscular, less aggressive) intersect to suggest what is appropriate for women athlete's gender expression (Krane, 2001).

Against a backdrop that privileges men's sport, and certain forms of masculinity (e.g., strong, muscular, aggressive), sport is a cultural site where the gender binary and heteronormativity are reinforced as 'natural' (Connell \& Messerschmidt, 2005; Krane, 2001). Women's sport is often positioned as 'less than' male, and when women athletes deviate from heterosexuality and/or femininity through embodying so-called masculine qualities (e.g., muscularity, strength, aggression), they may be marginalized and/or have their identities as women questioned (Blodgett et al., 2017; McGannon, Schinke et al., 2019; Schippers, 2007). Given that CSP is concerned with identity expression and inclusion, and that women athletes continue to experience marginalization, focusing on gender issues in women's sport is important.

Two autobiography studies by Stewart combined feminist theory with relativist narrative inquiry to examine two high profile sportswomen's identities and experiences across their sport careers. In the first study, British boxer Jane Couch's autobiography 'Fleetwood Assassin' was explored (Stewart, 2011) as a story of cultural significance in light of Couch's intersecting identities of working class, heterosexual, boxer/athlete and physicality. Stewart's analysis of Couch's story showed her identity literally taking shape through boxing, and the ways in which she (re)negotiated 'feminine' ideals concerning her body and athletic identity within male dominated boxing spaces in order to distance herself from 'being lesbian' or 'not looking feminine enough'. This autobiographical analysis further unpacked the pressures that sportswomen face to conform 
to a narrow narrative of femininity in order to attain control of their bodies and sport performance.

More recently, Stewart (2017) explored Welsh cyclist, Olympian and World Champion, Nicole Cooke's autobiography 'Breakaway' in relation to gender relations and discrimination within cycling culture. This analysis highlighted the detrimental psychological impact of sexism grounded in structural discrimination across Cooke's career, and lack of agency she experienced due to exclusion and political ramifications of reporting inequality. This analysis also highlighted how Cooke's intersecting identities of White, heterosexual, and middle class afforded her the opportunity to use her story post-retirement. Through her experiences and public story, Cooke raised awareness of inequality, contributing toward social justice for women's sport. Collectively, Stewart's work highlighted autobiography's analytic and pedagogical potential to raise awareness of problematic 'gender standards' and discriminatory practices that sportswomen are subjected to, and how autobiography exposes complex power issues that sportswomen negotiate.

Dawn Heinecken's (2016) 'jockography' study grounded in cultural studies and a social constructionist conception of female athletic self-identity, took a broader approach to exploring gender issues. This study examined 30 published autobiographies of high profile U.S. sportswomen (6 African American and 24 White) in a range of sports (e.g., swimming, gymnastics, track and field, soccer, basketball). Dawn Heinecken's analysis showed that, regardless of intersectional aspects of identity (e.g., race, class, athlete), all sportswomen negotiated their identities in ways that reinforced narrow notions of heterosexual femininity in order to gain access to power and privilege within sport spaces (e.g., sponsorship, media attention, career advancement). Similar to Stewart's findings within Couch's autobiography, these findings were pronounced for women negotiating success in 'male coded' sports (e.g., boxing, basketball) where aggression, muscularity and strength were assets. Athletes in 'feminized sports' (e.g., figure skating, gymnastics) drew on the gender binary of feminine vs. masculine, constructing powerful aspects of their physicality as the exception, which afforded access to men's power. By showing that women drew on narrow gendered narratives concerning femininity and sexuality within their stories, Heinecken's autobiographic study showed that confronting or calling out inequalities were less likely.

The final study published within sport psychology by Kerry McGannon, Erin Tatarnic and Jenny McMahon (2019) explored British track athlete Jo Pavey's autobiography 'This Mum Runs'. The aim of this work was to expand understanding of the nuanced gendered narratives concerning motherhood and sport. 
Pavey's story was culturally significant to focus on because many of her notable athletic achievements came after having two children. In particular, she won a bronze medal at the July 2014 Commonwealth Games ten months after giving birth to her second child and then won the gold medal in the $10,000 \mathrm{~m}$ at the European Championship in August, 2014. The following central theme was identified within the context of pregnancy and motherhood in relation to training and competition within Pavey's autobiography: discovery narrative-reconfiguring the performance narrative, along with two sub-themes: go with the flow and best of both worlds. The sub-themes identified within this work showed the complex navigation of tensions in relation to an athlete mother identity grounded in family relationships to facilitate training and competition goals, within a discovery narrative. The discovery narrative meanings characterized sport as conduit to enjoyment, and competition linked to personal growth. Applied sport psychology recommendations using narrative theory included using female athlete stories as concrete entry points (i.e., pedagogical resources) to encourage compatible athlete mother identities and sport career engagement. Such narratives contrasted with narratives of 'good motherhood' which position motherhood and athlete identities as incompatible, pressuring women to choose and/or navigate motherhood and athletic career with minimal support because women are 'naturally' suited to caregiving. This study added to the aforementioned autobiographic work on gender issues, and was the first autobiographic study to focus on elite athlete mother identities.

\section{Athlete Health and Well-being Issues}

Athlete health and well-being are complex research areas encompassing a range of findings stemming from psychological, clinical and sociological theorizing and research. Health and well-being can refer to 'mental health' as being on a continuum where psychological states do not interfere with functioning, to where one experiences low functioning along with psychological states consisting of a range of problematic cognitive, emotional, or behavioural characteristics (Schinke et al., 2018). A recent review of literature showed that elite athletes are vulnerable to experiencing mental health issues due to performance pressures, training regimes and environments that compromise health and well-being. These issues include, but are not limited to, depression, anxiety, eating disorders, stressors (e.g., injury, overtraining, career transition), substance use and addiction, and trauma related disorders (Reardon et al., 2019). Athlete mental health has recently come to the forefront, with two central organizational and academic bodies in sport psychology - The European Federation of Sport Psychology (FEPSAC) (Moesch et al., 2018) and International Society of Sport and Exercise Psychology (ISSP) (Schinke et al., 2018) - re- 
leasing position statements on elite athlete mental health. These statements synthesized key issues for researchers and practitioners to consider, as well as future areas of research on elite athlete mental health.

The socio-cultural realm is a growing area of focus to expand knowledge and research on athlete mental health. Relevant for CSP, is the exploration of the links between identity marginalization and/or identity foreclosure, adaptation and adjustment and mental health (Schinke et al., 2018). Sport psychology researchers have also drawn attention to the 'performance narrative' as contributing to sport cultures and practices that can compromise mental health. The performance narrative centralizes a singular athletic identity and striving for outcome-oriented results (e.g., winning, being the best, perfectionism) to the exclusion of other life pursuits (e.g., relationships, children, hobbies) (Carless \& Douglas, 2013; McGannon, Tatarnic, et al., 2019). When framed within this narrative, athletes' life stories follow a linear path of actions centring on rigid training regimes and physical and mental sacrifice. Problematizing the performance narrative allows researchers and practitioners to question, and show, the ways that it leaves athletes with a false sense of agency, to the exclusion of developing other aspects of identity and resources with which to adapt when personal setbacks occur, or if they become ill, injured, or retire (Carless \& Douglas, 2013).

Ted Butryn and Matthew Masucci (2003) published one of the first autobiographic studies in cultural studies, to explore the intersection of illness, bodyself relationships, and implications for identity meanings within an elite athlete's life journey. Working at the intersection of autobiographic studies and critical cultural studies, they analysed cyclist Lance Armstrong's autobiography 'It's Not About the Bike: My Journey Back to Life'. This text was used as a resource to explore Armstrong's experiences after cancer diagnosis, treatment and remission, and come back to win the Tour de France in 1999. Butryn and Masucci's (2003) critical analysis showed that Armstrong's body-self relationships intertwined with technology (e.g., medicine, sport equipment and training) which (re)created his body, identities and psyche in ways that compromised, and enhanced, his health. For example, when recovering from cancer, Armstrong relentlessly pursued physical conditioning through technology; this enhanced his performance and 'hero status', but also led to putting his body at risk and stress.

Andrew Sparkes (2004) extended the above work through a different analysis of Armstrong's autobiography grounded in Art Frank's (2013) work on illness narratives. This relativist narrative analysis of Lance Armstrong's autobiography demonstrated that disciplinary regimes (e.g., medical treatment, extreme 
physical training) also constructed his body-self relationships in. When drawing on a cultural 'narrative of restitution' which expects an ill person to return to 'good as new' through medical science, Armstrong constructed his ill-body and mind-set as needing to be returned to pre-cancer status. While this narrative facilitated Armstrong's outlook initially, the downside was that the reality of the cancer experience was stressful and characterized by fear and loss of an athletic identity. Armstrong eventually shifted to a 'quest narrative', which meets suffering and illness head on. A quest narrative allowed him to psychologically adjust to his changed body (e.g., scarred by surgery/treatment), accept himself, and make meaning of the illness to gain life perspective.

Stewart et al. (2011) conducted a more extensive social relational narrative analysis of 12 athlete autobiographies on a range of illnesses (e.g., depression, panic disorder, cancer, multiple sclerosis). The role of metaphor (i.e., the means by which experiences are described in relation to something else) using Art Frank's (2013) illness narratives, was explored within the stories. All 12 autobiographies drew upon a war metaphor within a restitution narrative, in the hope of restoring one's self and body back to pre-illness condition, using medical treatment and science. The notion of 'fighting the enemy' of illness was appropriated by athletes as a legacy linked to their identities as strong athletes who never waver or give up. In terms of psychological adaptation and adjustment, this metaphor served to propel some toward healing, but silenced the expression of distress and accepting that illness changes the self and that one's body is not always 'cured'. Related to this finding was also the use of the 'body as a machine' metaphor within a restitution narrative. This metaphor facilitated control for some athletes, but for others led to feeling isolated and broken when they could not be 'fixed' like a machine. The metaphor of 'life as a journey' within a quest narrative allowed athletes to (re)create their identities through distancing themselves from dark memories and gain perspective.

While the autobiographic studies above did not explore the intertwining of gender, it is useful to draw attention to the potential role of gender ideologies using the concept of 'hegemonic masculinity' (Connell \& Messerschmidt, 2005). 'Hegemonic masculinity' is a culturally idealized form of 'being a man' and can be used to explain how and why men maintain dominant social roles over women, and other gender identities, which are perceived as 'feminine' and therefore less desirable (Schippers, 2007). Within sport, certain cultural ideals of masculinity (e.g. control, less emotion, strength, success tied to bodily sacrifice and pain) afford those who confirm to these ideals with power and privilege. The restitution and quest narratives identified within Armstrong's story that both compromised and enhanced his health, are further understood 
against a backdrop of these hegemonic masculine ideals of what it means to be a 'male athlete' (e.g., fit, strong, cancer-free, heroic). Within Lance Armstrong's autobiography, the pursuit of these so-called masculine ideals through the adoption of bodily regimes, afforded him dominance, power and privilege in his sporting career, despite the personal pain and sacrifice involved (Butryn \& Masucci, 2003).

Applied to the larger autobiographic study on illness and the role of metaphors by Stewart et al (2011), the concept of hegemonic masculinity also affords the opportunity to delve deeper into the role of taken for forms or language use (i.e., metaphors) as perpetuating masculine ideals. These ideals work to advantage adaption and adjustment for some, but also disadvantage and silence mental health issues or expression of distress, for others. For example, the use of war metaphors such as 'fighting the enemy' and the ties to a strong athletic body identified within a restitution narrative, may be further read as masculine (Sparkes, 2004), as these are linked to denial of emotion and hiding vulnerability. As noted, some athletes conforming to these ideals when drawing on a restitution narrative within their stories experienced stigma, shame, pain and denial of their experiences. The use of 'masculine metaphors' also privileged some athletes and aligned with their experiences, but also silenced others whose illness trajectory and experiences do not conform.

In one of the first published autobiographic studies in sport psychology, Karen Howells and David Fletcher (2015) built on athlete identity and health research by exploring eight autobiographies of Olympic swimmers' experiences of adversity (e.g., mental or physical illness, family stressors, silenced sexualities, addiction, and abuse). This study was grounded in a psycho-social approach to narrative inquiry to explore the unfolding process of adaptation to adversity. Their narrative analysis showed that swimmers initially sought normalcy through an emotional and physical connection with swimming within their stories. Using a connection with the water in this manner pushed traumatic disclosure to the background. In turn, athletes developed public (e.g., a disciplined, controlled, and confident athlete) and private (e.g., an insecure, distressed athlete) identities, which compounded health related issues (e.g., eating disorders, depression, anxiety, self-harm, drug and alcohol abuse). Athletes were able to shift these maladaptive practices and fractured identities by problematizing the performance narrative and shifting to a quest narrative. The support from others (e.g., coaches, family, and therapist) was key in facilitating the use of cultural narratives to facilitate athlete's growth, spiritual awareness, and prosocial behaviour. 
The autobiographic research reviewed thus far is valuable for sport psychology researchers and practitioners, interested in athlete mental health. Such work opens up access to difficult topics such as physical and mental illness and allows for an additional critical lens and analysis dimension, not available through reading the stories on one's own. The additional advantage of this autobiographic research with a CSP lens, is that performance and restitution narratives assumed useful for mental health and performance, can be identified as problematic. These narratives may silence athletes and/or impact identity construction and adjustment in a number of ways, with positive and difficult forms of adjustment for athletes. While such studies in sport psychology are rare, Hannah Newman et al. (2016) further showed the value in studying athlete autobiographies to gain access to the often stigmatized topic of athlete mental health, through a detailed focus on depression in 12 athlete autobiographies. Again, taking a psycho-social approach to narrative which views stories as reflections of mental states, this study shed light on influences outside of, and within, sport culture that make athletes vulnerable to depression. These influences included life stressors such as family (e.g., parental divorce, parental pressure), relying on tangible results (e.g., winning, medals, performance goals) for self-worth and acceptance by others (e.g., teammates, family, coaches), and intense emotional reaction to failure linked to perfection. The foregoing influences intertwined with depressive symptoms and a singular athlete identity, which negatively influenced sport engagement and performance, opening up discussions of developing proactive approaches to depression prevention, detection and management.

A recent study in sport psychology used social-relational narrative inquiry to study disordered eating meanings and experiences of two Olympic female swimmers' - Amanda Beard and Leisel Jones - struggle and recovery as socially constructed within their stories (McGannon \& McMahon, 2019). Two cultural narratives were identified within Beard's and Jones' autobiographies: performance narrative and struggle and personal growth narrative. These narratives framed turning points within the stories connected to body-self relationships body and relationship turning points (linked to struggle) and emotional and body acceptance turning points (linked to recovery). These findings build upon the aforementioned autobiographical research in cultural studies and sport psychology, which shows the value of studying elite athletes' stories as theoretical, methodological and pedagogical resources to learn more about athlete health and well-being. This study also showed the intersection of gendered disordered eating meanings of struggle and recovery within elite swimming culture as nuanced personal and cultural processes across female athletes' careers. Aligning with the work reviewed earlier on sportswomen and gender, this 
study on gender and athlete health expands ways to use autobiographies as pedagogical resources to harness relational narratives (e.g., support from family, therapist or practitioner) to facilitate additional understandings of female athlete's recovery.

\section{Future Research and Concluding Reflections}

The use of narrative inquiry in conjunction with athlete autobiographies as data resources, is a research avenue that embraces personal and public forms of stories as cultural sites of analysis, to expand understanding of self-identity, sport participation and performance issues in a range of sport contexts. Autobiographic studies grounded in narrative inquiry are growing in sport psychology, because autobiographical analysis adds to, and expands, sport psychology research. Such work has allowed researchers to show that narratives matter for elite athlete identity expression and inclusion, mental health, well-being and performance (Blodgett et al., 2017; Carless \& Douglas, 2013; Howells \& Fletcher, 2015; Newman et al., 2016; McGannon, Schinke et al., 2019; McGannon \& McMahon, 2019; Smith et al., 2016). In terms of CSP's central focus on identity expression and inclusion within the context of social justice, autobiographies have much to offer toward adding to, and expanding, the CSP research agenda.

Moving forward there are several future research avenues that sport psychology researchers interested in working at the intersection of narrative inquiry and autobiographic studies, might consider. The first of these to explore a more diverse range of athlete autobiographies from different sport cultures and countries/geographic regions. The published autobiographic work that we reviewed has focused on White, able-bodied, middle class, heterosexual athletes, from European and/or Western cultures. Studying athlete autobiographies from other identity, social and cultural backgrounds in terms of social class, race, sexuality, (dis)ability, physicality and gender identities would expand the CSP research agenda concerning understanding identity expression and inclusion. In terms of gender, health and well-being issues, the autobiographic research landscape is wide-open for exploration, particularly given that elite and professional athletes are coming forward to tell their stories as forms of disclosure and witness, to destigmatize mental illness and/or identity struggles that impact sport performance. In this regard, a range of gender, mental health and self-identity related issues might be included on the CSP research agenda, as disclosed through published athlete and sporting autobiographies. Such topics might include addiction (e.g., sex, gambling, drugs, and alcohol), sexuality, homophobia, career transition, sport injury and/or illness, and forms of trauma (e.g., abuse, domestic violence). Autobiographical data sources might come 
from published books (digital, audio, textual), film, television or digital media spheres (e.g., websites, blogs, podcasts).

Finally, given that narrative inquiry and autobiography point to stories 'doing things' and having behavioural effects, a focus on research exploring autobiography as a pedagogical tool to learn more about how stories are used and impact others, would be of value. Future research in this regard could invite athletes and researchers to be storytellers - recreational, competitive, elite - to write first person short autobiographies in relation to cultural identities, sport participation and/or performance. Stories could be analysed for content, structure and cultural meanings, within the context of socio-cultural narrative resources, and linked to psychological, behavioural and social implications. Autobiographies on various gender, health and performance issues and the role of sport culture can also be shown to stakeholders (e.g., coaches, teammates, sports medicine staff), who can then be interviewed individually or in focus groups. The exploration of the narrative resources used to make sense of the stories, and how such stories affect their own practices, would be of interest. The foregoing ideas and research outlined in the present paper are a modest starting point for what we hope will be continued stimulation and growth concerning narrative and autobiographical research forms, to learn more the social construction of identity in relation to sport participation and performance.

\section{REFERENCES}

Blodgett, Amy T.; Schinke, Robert J.; McGannon, Kerry R. \& Fisher, Leslee A. (2015). Cultural sport psychology research: Conceptions, evolutions and forecasts. International Review of Sport and Exercise Psychology, 8(1), 24-43.

https://doi.org/10.1080/1750984X.2014.942345

Blodgett, Amy T.; Ge, Yang; Schinke, Robert J. \& McGannon, Kerry R. (2017). Intersecting identities of female boxers: Stories of cultural difference and marginalization in sport. Psychology of Sport and Exercise, 32, 83-92.

https://doi.org/10.1016/j.psychsport.2017.06.006

Brewer, Britton W.; Van Raalte, Judy L. \& Linder, Darwyn E. (1993). Athletic identity: Hercules' muscles or Achilles heel? International Journal of Sport Psychology, 24(2), 237-254.

Butler, Judith (2006). Gender trouble: Feminism and the subversion of identity. Routledge.

Butryn, Ted M. (2002). Critically examining White racial identity and privilege in sport psychology. The Sport Psychologist, 16(3), 316-336.

Butryn, Ted M., \& Masucci, Matthew A. (2003). It's not about the book: A cyborg counter narrative of Lance Armstrong. Journal of Sport and Social Issues, 27 (2), 124-144. https://doi.org/10.1177/0193732503252176 
Carless, David, \& Douglas, Kitrina (2013). Living, resisting, and playing the part of athlete: Narrative tensions in elite sport. Psychology of Sport and Exercise, 14(5), 701708. https://doi.org/10.1016/j.psychsport.2013.05.003

Connell, R.W., \& Messerschmidt, James W. (2005). Hegemonic masculinity: Rethinking the concept. Gender \& Society, 19(6), 829-859. https: / / doi.org/10.1177/0891243205278639

Eakin, Paul J. (2008). Living life autobiographically: How we create identity in narrative. Cornell University Press.

Fisher, Leslee A.; Butryn, Ted M., \& Roper, Emily A. (2003). Diversifying (and politicizing) sport psychology: A promising perspective. The Sport Psychologist, 17(4), 391405.

Frank, Arthur (2013). The wounded storyteller ( $2^{\text {nd }}$ edition). The University of Chicago Press.

Gill, D. (2001). In search of feminist sport psychology: Then, now, and always. The Sport Psychologist, 15, 363-449.

Heinecken, Dawn (2016). Gender and jockography: Post-feminism resistance in female sports autobiographies. Feminist Media Studies, 16(2), 325-343.

https: / / doi.org/10.1080/14680777.2015.1052006

Howells, Karen, \& Fletcher, David (2015). Sink or swim: Adversity-and growth-related experiences in Olympic swimming champions. Psychology of Sport and Exercise, 16(3), 37-48. https://doi.org/10.1016/j.psychsport.2014.08.004

Krane, Vikki (2001). One lesbian feminist epistemology: Integrating feminist standpoint, queer theory and cultural studies. The Sport Psychologist, 15, 401-411. https://doi.org/10.1123/tsp.15.4.401

McMahon, Jenny (2016). Creative analytical practices. In. Brett Smith \& Andrew C. Sparkes (Eds.). International Handbook of Qualitative Methods in Sport and Exercise (pp. 302-315). Routledge.

McGannon, Kerry R., \& McMahon, Jenny (2019). Understanding female athlete disordered eating and recovery through narrative turning points in autobiographies. Psychology of Sport and Exercise, 40, 42-50.

https://doi.org/10.1016/j.psychsport.2018.09.003

McGannon, Kerry R.; Schinke, Robert J. \& Busanich, Rebecca (2014). Cultural sport psychology: Considerations for enhancing cultural competence of practitioners. In Lauren S. Tashman \& Gilbert Cremades (Eds.) Becoming a sport, exercise, and performance psychology professional: International perspectives (pp. 135-142). Routledge.

McGannon, Kerry R.; Schinke, Robert J.; Ge, Yang \& Blodgett, Amy T. (2019). Negotiating gender and sexuality: A qualitative analysis of elite women boxer intersecting identities and sport psychology implications. Journal of Applied Sport Psychology, 31(2),168-186. https:// doi.org/10.1080/10413200.2017.1421593

McGannon, Kerry R., \& Smith, Brett (2015). Centralizing culture in cultural sport psychology research: The potential of narrative inquiry and discursive psychology. Psychology of Sport and Exercise, 17, 79-87. https://doi.org/10.1016/j.psychsport.2014.07.010 
McGannon, Kerry R.; Smith, Brett; Kendellen, Kelsey, \& Gonsalves, Christine A. (2019). Qualitative research in six sport and exercise psychology journals between 20102017: An updated and expanded review of trends and interpretations. International Journal of Sport and Exercise Psychology. Advance online publication. https://doi.org/10.1080/1612197X.2019.1655779

McGannon, Kerry R., \& Spence, John C. (2010). Speaking of the self and physical activity participation: What discursive psychology can tell us about an old problem. Qualitative Research in Sport and Exercise, 2(1), 17-38. https: / / doi.org/10.1080/19398440903510145

McGannon, Kerry R.; Tatarnic, Erin, \& McMahon, Jenny (2019). The long and winding road: An autobiographic study of an elite athlete mother's journey to winning gold. Journal of Applied Sport Psychology, 31(4), 385-404. https://doi.org/10.1080/10413200.2018.1512535

Moesch, Karin; Kentta, Goran; Kleinert, Jens; Quignon-Fleuret, Cedric; Cecil, Sarah, \& Bertollo, Maurizio. (2018). FEPSAC position statement: Mental health disorders in elite athletes and models of service provision. Psychology of Sport and Exercise, 38, 61-71. https://doi.org/10.1016/j.psychsport.2018.05.013

Newman, Hannah J.; Howells, Karen L., \& Fletcher, David (2016). The dark side of top level sport: An autobiographic study of depressive experiences in elite sport performers. Frontiers in Psychology, 7, 1-12. https://doi.org/10.3389/fpsyg.2016.00868

Pipkin, James (2008). Sporting lives: Metaphor and myth in American sports autobiographies. University of Missouri Press.

Reardon, Claudia L.; Hainline, Brian; Miller Aron, Cindy; Baron, David; Baum, Antonia L.; Bindra, Abhinav; Budgett, Richard; Campriani, Niccolo; Castaldelli-Maia, João Mauricio; Currie, Alan; Derevensky, Jeffrey L.; Glick, Ira D.; Gorczynski, Paul; Gouttebarge, Vincent; Grandner, Michael A.; Hyun Han, Doug; McDuff, David; Mountjoy, Margo; Aslihan, Polat; Purcell, Rosemary... Engebretsen, Lars. (2019). Mental health in elite athletes: International Olympic Committee consensus statement. British Journal of Sports Medicine, 53(11), 667-699. http://dx.doi.org/10.1136/bjsports2019-100715

Ronkainen, Noora J.; Kavoura, Anna, \& Ryba, Tatiana V. (2015). A meta-study of athletic identity research in sport psychology: Current status and future directions. International Review of Sport and Exercise Psychology, 9(1), 45-64. https: / / doi.org/10.1080/1750984X.2015.1096414

Ronkainen, Noora J.; Kavoura, Anna, \& Ryba, Tatiana V. (2016). Narrative and discursive perspectives on athlete identity: Past, present and, future. Psychology of Sport and Exercise, 27, 128-137. https://doi.org/10.1016/j.psychsport.2016.08.010

Ryba, Tatiana V.; Schinke, Roberts J., \& Tenenbaum, Gershon (Eds.). (2010). The cultural turn in sport and exercise psychology. Fitness Information Technology.

Ryba Tatiana V.; Stambulova, Natalia; Si, Gangyan, \& Schinke, Robert J. (2013). ISSP position stand: Culturally competent research and practice in sport and exercise psychology. International Journal of Sport and Exercise Psychology, 11(3), 123-142. https://doi.org/10.1080/1612197X.2013.779812

Schinke, Robert J.; Stambulova, Natalia B.; Lidor, Ronnie; Papaioannou, Athanasios, \& Ryba, Tatiana V. (2016). ISSP position stand: Social missions through sport and exer-

http://quadernsdepsicologia.cat 
cise psychology. International Journal of Sport and Exercise Psychology, 14(1), 4-22. https://doi.org/10.1080/1612197X.2014.999698

Schinke, Robert J.; Stambulova, Natalia B.; Si, Gangya, \& Moore, Zella. (2018). International society of sport psychology position stand: Athletes' mental health, performance, and development. International Journal of Sport and Exercise Psychology, 16(6), 622-639. https://doi.org/10.1080/1612197X.2017.1295557

Schippers, Mimi (2007). Recovering the feminine other: Masculinity, femininity and gender hegemony. Theory \& Society, 36, 85-102. https://doi.org/10.1007/s11186007-9022

Slater, Matthew J.; Barker, Jamie B.; Coffee, Pete, \& Jones, Marc V. (2015). Leading for Gold: Social identity leadership processes at the London 2012 Olympic Games. Qualitative Research in Sport, Exercise, and Health, 7(2), 192-209. https://doi.org/10.1080/2159676X.2014.936030

Smith, Brett (2010). Narrative inquiry: Ongoing conversations and questions for sport and exercise psychology research. International Review of Sport and Exercise Psychology, 3(1), 87-107. https://doi.org/10.1080/17509840903390937

Smith, Brett. (2016). Narrative analysis in sport and exercise: How can it be done? In Brett Smith \& Andrew C. Sparkes (Eds.), Routledge handbook of qualitative research in sport and exercise (pp. 260-273). Routledge.

Smith, Brett; Bundon, Andrea, \& Best, Melanie (2016). Disability sport and activist identities: A qualitative study of narratives of activism among elite athletes' with impairment. Psychology of Sport and Exercise, 26, 139-148.

https://doi.org/10.1016/j.psychsport.2016.07.003

Smith, Brett \& Sparkes, Andrew (2008) Contrasting perspectives on narrating selves and identities: An invitation to dialogue. Qualitative Research, 8(1), 5-35.

https://doi.org/10.1177/1468794107085221

Smith, Brett, \& Sparkes, Andrew C. (2009). Narrative inquiry in sport and exercise psychology: What can it mean, and why might we do it? Psychology of Sport and Exercise, 10(1), 1-11. https://doi.org/10.1016/j.psychsport.2008.01.004

Smith, Sidonie, \& Watson, Julia (2010). Reading autobiography: A guide for interpreting life narratives (2nd ed.). University of Minnesota Press.

Sparkes, Andrew C. (2004). Bodies, narratives, selves, and autobiography: The example of Lance Armstrong. Journal of Sport and Social Issues, 28(4), 397-428. https: //doi.org/10.1177/0193723504269907

Sparkes, Andrew C., \& Stewart, Carly (2016). Taking sporting autobiographies seriously as an analytical and pedagogical resource in sport, exercise and health. Qualitative Research in Sport, Exercise and Health, 8(2), 113-130. https://doi.org/10.1080/2159676X.2015.1121915

Stewart, Carly (2011). Packing a punch for the feminist project? The autobiography of Jane Couch. In Andrew C. Sparkes (Ed.), Auto/Biography 2010 Yearbook (pp. 95111). Russell Press.

Stewart, Carly (2017). Utilizing sporting autobiographies for feminist research: The case of cyclist Nicole Cooke. In Louise Mansfield, Jane Caudwell, Belinda Wheaton \& 
Beccy Watson (Eds.), The Palgrave handbook of feminism and sport, leisure and physical education (pp. 293-311). Palgrave Macmillan.

Stewart, Carly; Smith, Brett \& Sparkes, Andrew (2011). Sporting autobiographies of illness and the role of metaphor. Sport in Society, 14(5), 581-597.

https://doi.org/10.1080/17430437.2011.574358

\section{KERRY R. MCGANNON}

Is a Professor in Sport and Exercise Psychology. Her research program focuses on socio-cultural issues in sport and exercise related to identities and critical interpretations of topics related to health, well-being and performance. She is Co-Editor of the journal Qualitative Research in Sport, Exercise and Health.

kmcgannon@laurentian.ca

https://orcid.org/0000-0002-8614-697X

\section{BRETT SMITH}

Is a Professor of disability and physical activity, and Department Director of Research. His research is underpinned by ideas from psychology, sociology, public health, and critical disability studies. He is the President of the International Society of Qualitative Research in Sport and Exercise (https: //www.qrsesoc.com) brett.smith@durham.ac.uk https://orcid.org/0000-0001-7137-2889

\section{FORMATO DE CITACIÓN}

McGannon, Kerry R. \& Smith, Brett (2020). Expanding socio-cultural identity research in sport psychology: The potential of athlete autobiographies. Quaderns de Psicologia, 22(3), e1556. http://dx.doi.org/10.5565/rev/qpsicologia. 1556

\section{HISTORIA EDITORIAL}

Recibido: 15-07-2019

$1^{\text {a }}$ revisión: $10-07-2020$

Aceptado: $13-07-2020$

Publicado: $11-12-2020$ 